This item was submitted to Loughborough's Research Repository by the author.

Items in Figshare are protected by copyright, with all rights reserved, unless otherwise indicated.

\title{
Articulating dissident citizenship, belonging, and queerness on cyberspace
}

PLEASE CITE THE PUBLISHED VERSION

http://www.southasianliteraryassociation.org/south-asian-review/

\section{PUBLISHER}

(c) South Asian Literary Association

\section{VERSION}

AM (Accepted Manuscript)

\section{PUBLISHER STATEMENT}

This work is made available according to the conditions of the Creative Commons Attribution-NonCommercialNoDerivatives 4.0 International (CC BY-NC-ND 4.0) licence. Full details of this licence are available at: https://creativecommons.org/licenses/by-nc-nd/4.0/

\section{LICENCE}

CC BY-NC-ND 4.0

\section{REPOSITORY RECORD}

Dasgupta, Rohit K.. 2019. “Articulating Dissident Citizenship, Belonging, and Queerness on Cyberspace”. figshare. https://hdl.handle.net/2134/25211. 


\title{
Articulating Dissident Citizenship, Belonging, and Queerness on Cyberspace
}

\author{
Rohit K. Dasgupta \\ Winchester School of Art, University of Southampton \\ (U.K.)
}

[Abstract: On December 11, 2013, the Indian Supreme Court reinstated Section 377, which criminalizes sexual acts "against the order of nature." This article is a meditation on the acts of individual and collective resistance undertaken by dissident citizens (Sparks) in order to challenge and articulate strategies to intervene and critique the State and civil society's role in this decision. Activism is the study of the relationship between the virtual and the actual (Dave). Using three case studies, this article examines how dissident, queer citizens attempt to create queer counter-publics on digital space, thereby claiming a performative and participative form of citizenship. I extend Dave's study of activism by drawing upon a range of experiences of activists and civilians "within the field" alongside the digital articulation and assimilation of these movements.]

Tstarted writing this article at a very critical time during the history of 1 the queer movement in India. The Supreme Court ruling on Section 377 had just come in, displacing the Delhi High court's ruling that had decriminalized homosexuality in 2009 , reinstating what was a Victorian law back into the culture and social fabric of the country. While the law does not criminalize gay identity itself, it does criminalize a sexual act, thus effectively criminalizing most (if not all) queer-identified individuals in the country. Discussions on sexual culture in India have always had a ritualistic and an abject invocation of the Kamasutra and the Gandhian discourse on the erasure of desire (Srivastava 1). This anxiety and concern over sexuality stretches far back to colonial times, South Asian Review, Vol. 35, No. 3, 2014 
both at the level of the State, which went out of its way to regularize practices, as well as non-state actors, who had a personal stake in exercising and controlling certain aspects of this (Ballhatchet 3). During the colonial period, this was particularly done through the poets Altaf Hussayn Hali (1837-1914) and Muhammad Husayn Azad (18341910), whereby a radical "ethical cleansing" of the homoerotic texts took place (Kugle 40). The Indian state's adoption of the Sodomy Law of 1860, with its homophobic/masculinist and heteronormative bias, is in many ways an endorsement of the colonial control of sexuality.

It is imperative to situate the queer movement within the political and social context of postcolonial India, which, as Brinda Bose and Shuddhabrata Bhattacharya have pointed out, is complex. The colonial role in creating and sustaining anxiety over non-normative sexualities (Kugle 40) and the orientalist hypersexualization of Indian culture (Srivastava 2) are major influences in the creation of a heteronormative (and homophobic) monoculture. Bose and Bhattacharya have argued that questions of identity are complex to begin with and become more so when confronted by national specificities (x).

The citizen has existed as a key component of the nation-building exercise, increasingly becoming a contested entity with critics based on race, disability and sexuality. These differences impact how different people experience citizenship (Bachcheta 141). Paola Bachcheta uses the term "xenophobic queerphobia," which implies a particular form of queer phobia that is justified by constructing the queer individual outside the nation (144). By this logic, she is claiming that Indian nationalists see queer as "non-Indian." By placing queerness as a foreign object, she argues, Hindu nationalists dissociate themselves from the queer figures, who, according to them, embody the antinationalist, sexually promiscuous, materialistic and Western attitudes. Sara Ahmed has argued that the queer figure exists within a heterosexual, patriarchal monoculture, where it confronts and unsettles the normative, "looking strange and out of place" (132). This confrontation between the dissenting queer citizen and the state gives rise to queer activism in India.

I explore the acts of resistance and collective as well as simultaneous efforts by dissident citizens to challenge and articulate strategies to critique civil society's ${ }^{1}$ role in the Supreme Court decision. To study activism would be to study the relationship between the virtual and the actual. As Naisargi Dave notes in her introduction to Queer Activism in India, "activism begins, then, precisely as the virtual in the actual world, the previously unthinkable that is now a flickering possibility, just on the verge of entering upon the world of norms" (10). In this article, I extend Dave's study of activism by drawing upon a range of ethnographic experiences of activists and civilians "within the 
Articulating Dissident Citizenship, Belonging, and Queerness 205

field" alongside the digital articulation and assimilation of these movements on the cyberspace. ${ }^{2}$ In the following sections, I turn to some of these practices that characterize representations of dissident citizenship.

At the heart of this movement is the dissident citizen and the notion of dissident citizenship. Holloway Sparks characterizes this as "the practices of marginalized citizens who publicly contest prevailing arrangements of power by means of oppositional democratic practices that augment or replace institutionalized channels of democratic opposition when those channels are inadequate or unavailable" (75). Building on Sparks' definition, I extend the definition of a dissident queer citizen of India as one who continually challenges the law through their very public existence, imagining and critiquing new queer political practices, and confronting public perceptions of queerness. This includes creative practices, digital activism as well as an articulation of "being queer" in the public sphere.

\section{Dissident Citizenship}

The concept of sexual citizenship was first employed by David Evans in 1993 as a way of focusing attention on rights to a range of sexual identities and practices linked to the State. By recognizing the sexual nature of citizenship, he was arguing that existing models of citizenship are based on a hetero-patriarchal principle that does not embrace the diversity of sexual (practices) and identity of the people under its umbrella. This is extremely useful in theoretically framing narratives of rights discourse within the queer movement in India and elsewhere. Jeffrey Weeks has argued that all new sexual social movements are characterized by two moments - citizenship and transgression (45). In articulating a form of sexual citizenship, it is also imperative to recognize that, in principle, the State is supposed to serve the rights and choices of its citizens, thus any fight for recognition, respect and rights is also an indictment against the functional failure of the State. Gayatri Spivak and Judith Butler have, in a recent conversation, pointed out:

The state is supposed to service the matrix for the obligations and prerogatives of citizenship. It is that which forms the conditions under which we are juridically bound. We might expect that the state presupposes modes of juridical belonging, at least minimally, but since the state can be precisely what expels and suspends modes of legal protection and obligation, the state can put us, some of us, in quite a state. It can signify the source of non-belonging, even produce that non belonging as a quasi-permanent state. (3-4)

Spivak and Butler are undoubtedly correct about the limitations that the state imposes on citizenship. The crucial role of the State, in creating a 
dialectic, demarcates and reflects the complexity between the transgression of (sexual) norms by citizens and the legal and moral standpoint of the State. Spivak and Butler draw upon Hannah Arendt's theories of statelessness to argue that the nation state produces the stateless and confers non-belonging on national minorities. By placing the minority outside the polity, Spivak and Butler claim that this deprivation of citizenship empowers the citizen, offering a form of political resistance to the production of state subjects without legal rights, such as the queer citizen in India.

Weeks has identified three aspects (themes) that contribute to the making of the sexual citizen: democratization of relationships, new subjectivities, and the development of new (sexual) stories. The sexual citizen, according to him, is "simply an index of the political space that needs to be developed rather than a conclusive answer to it" (Weeks 48). The transformation of politics, especially in the western world, has accordingly brought about new problems, agendas and possibilities. According to Weeks, the sexual citizen is at the heart of this new contemporary politics "because they are centrally concerned with the quality of life" (49). This concern with the quality of life goes against the Indian nationalist tenet of "good sexuality," being concerned with family and reproductive rights, and "bad sexuality," pertaining to sexual enjoyment (Srivastava 5). Much of the criticism against the decriminalisation of Section 377 is about the decline in the moral and social fabric of the country, an argument that would follow. In the context of India, drawing on Sanjay Srivastava's recent work in Indian sexuality, it can be argued that sexuality and the family are of particular concern to the state, as these two contexts affect the "foundations of society" (11). The fraught status of homosexuality and queerness in the Indian society, especially within social movements that aspire to state power (which was granted momentarily in 2009 and the subsequent recriminalization in 2013) also points to the ways in which sexual (minority) citizens exist within a temporal space in the nation. Scholars, such as Sharif Mowlabocus, have argued that the digital is rooted within the gay male subculture, with the notion of finding a "safe space" at the core of this (7). The queer cyberspace, unbounded by geography, exists as a public sphere that offers a democratic scope for queer men to engage with issues around identity, belonging and community. Ram Murti, one of the petitioners to the High Court judgement, has argued: "The population of these people (queer citizens) is $0.2 \%$ and $99.8 \%$, the entire Nation gets affected ... this is a serious problem for our culture and core values" (qtd. in Kaushal 124).

Not only does he claim that the population of the LGBT community in India is $0.2 \%$ but also he refers to the remaining $99.8 \%$ as the "entire Nation" thus failing to recognize the queer 
Articulating Dissident Citizenship, Belonging, and Queerness 207

citizen/individual as a part of the Nation. The complex location of sexuality within national and nationalist histories is primarily a site for enhancing the reproductive capacities of the Nation (Srivastava 15). In this regard, sexual minorities threaten the national imaginary by defining sexuality for pleasure and not necessarily reproduction. Thus, even the significant minority of $0.2 \%$ critiques the reproduction narrative and the heterosexual expectations of the State from its people. This national critique is significant in order to understand Ram Murti's anxiety in excluding the queer citizen from the "entire nation."

\section{TV9}

On February 22, 2011, almost one and half years after the historic Delhi High Court judgement which read down Section 377, a television channel in Hyderabad ran a sinister story about "Gay Culture Rampant in Hyderabad." The story, which was based on a series of sting operations on the popular gay social networking/dating website Planet Romeo, showed a reporter logging into the website and chatting with gay men. The respondents were asked loaded questions about their sexual lives on the telephone, and all of this, unbeknownst to them, was broadcast on television without blocking out the faces or names of individuals. The program ended with the reporter morally concluding that "[a] lot of employees in higher positions, white collared workers, highly qualified students are becoming slaves to a lifestyle which is against nature" ("Gaysi" n. pag.). This was rebroadcast the next day despite protests from the queer community in India.

On behalf of Adhikaar, a LGBT Human Rights organization based in New Delhi, Aditya Bandyopadhyay sent a notice to TV9, under the National Broadcasters Association Guidelines, giving an ultimatum to the channel to either redress the situation or risk the threat of dealing with the News Broadcasters Association (NBA) Complaints redressal procedure. Bandyopadhyay primarily raised nine points of contention which were based on the infringement of privacy through entrapment, but, in the final point, Bandyopadhyay invokes Section 377:

\footnotetext{
After the Delhi High Court judgment reading down Section 377 of the Indian Penal Code, private consensual adult homosexuality is no more a criminal activity in India. Therefore, you have by this telephonic sting violated the NBA mandated ground rule that a news channel will ensure that a sting operation is carried out only as a tool for getting conclusive evidence of wrong doing or criminality. (Bandyopadhyay)
}

Bandyopadhyay's swift reaction to the TV9 episode was widely acknowledged; Facebook petitions were set up and the notice shared by several individuals and activists. It also sparked a discussion on the sting operation's act of forcing several people to rethink their visibility 
on public, and especially electronic, spaces. One of the most interesting responses to the sting operation was by Sushil Tarun, who commented on the Gaysi webpage: ${ }^{3}$

To use the real names of people without their permission was most unethical and outrageous. Would such a channel dare do a sting on straight men who frequent brothels or dance bars? Imagine if all the guys who went to a disco hoping to find a date with the opposite sex were treated like this? Such behaviour has to be roundly condemned, so that it never happens again. But there is an important lesson for the entire gay community. We must organize and act in ways so that our lives are accepted and respected in broad daylight. Whether we seek partners for sex or for love, we need to be treated with dignity and equality. That means that we still have a huge task ahead of us in educating the Indian public, so that people can learn to accept us without being judgemental or unkind. ("Gaysi” n. pag.)

Sushil's comment embodies the social and emotional complexity that the TV9 report brought forth. In envisioning and categorizing the queer subject, TV9 was using the discourse of unnatural sexual deviants, people who needed to be named and shamed for their sexual practices which went "against nature." They were also targeting PR; and the two targeted individuals in the sting were not publicly out about their orientation. What Sushil's comment brings to light is the need for education and advocacy within the general populace to lessen the stigma around being queer, which would vis-a-vis develop new understandings of the experience of queer men and the queer subject in India better. Sushil's comment also indicates that queer lives need to be respected in "broad daylight," again an indictment of the simple reading down of Section 377.

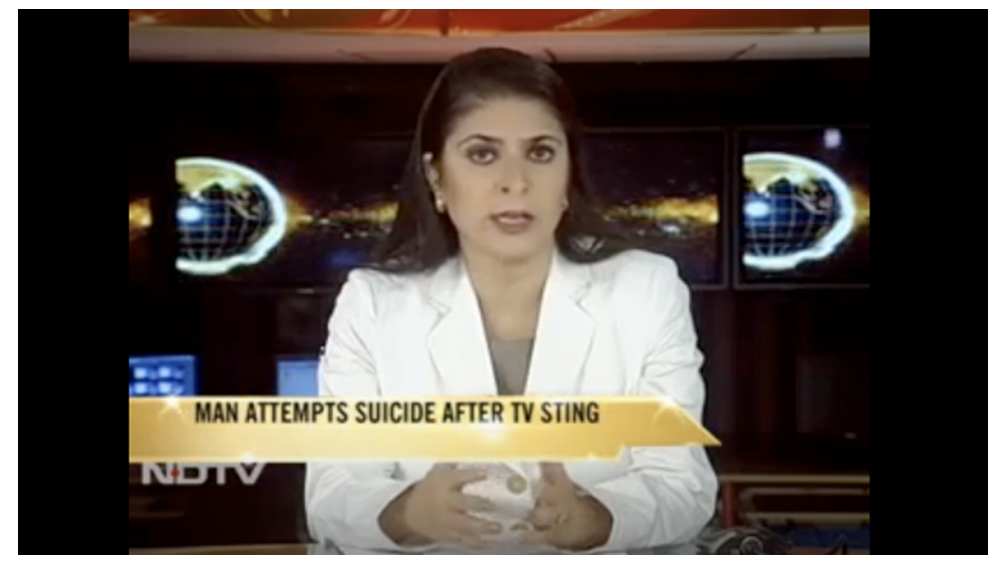


Articulating Dissident Citizenship, Belonging, and Queerness 209

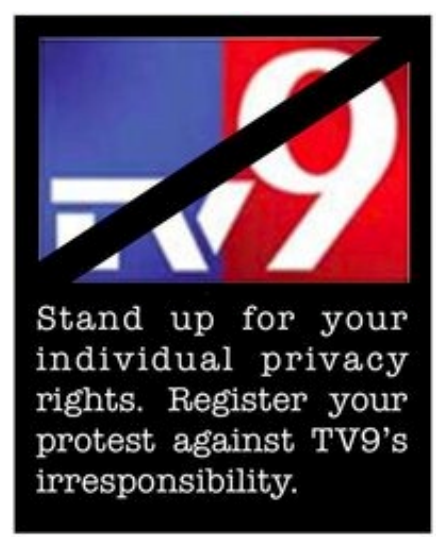

Bandyopadhyay and Adhikaar's notice made its way to the News Broadcasting Standards Authority (NBSA) in New Delhi, India, which issued a notice to the channel on February 24th asking the channel to respond within the stipulated fourteen days. TV9 defended their investigative journalism for bringing to public knowledge activities that were enticing people to "illegal and unlawful activities" ("Gaysi"). They further defended themselves by saying that the dating website was public, thus there was no privacy violation (deigning to mention that they had to make an account as a queer man to join the website in the first place). The NBSA and Justice [Retd.] S. Verma, who presided over the case, dismissed TV9's justification, censuring the channel for creating a sensationalized report about gay culture in Hyderabad. They also took notice of the reading down of 377 by the Delhi High Court and pointed out that same sex activity/ queer sexual orientation was no longer a criminal act in India:

The Programme needlessly violated the right to privacy of individuals with possible alternate sexual orientation, no longer considered taboo or a criminal act; and the Programme misused the special tool of a "sting-operation" available only to subserve the larger public interest. (“Gaysi”) ${ }^{4}$

NBSA also pointed out that TV9's claim that photographs, personal information and telephone numbers of the people targeted in the sting operation as "being public" was invalid as they were behind a membership area. The NBSA finally issued a fine of 100,000 rupees and telecast an apology for three consecutive days expressing their regret over the incident through the following text:

TV9 apologizes for the story 'Gay Culture Rampant in Hyderabad' telecast on this channel on 22nd February, 2011 from 15:11 hrs. to 15:17 hrs. particularly since the story invaded the privacy of certain 
persons and was in violation of the Code of Ethics \& Broadcasting Standards of the News Broadcasters Association. Any hurt or harm caused to any person thereby is sincerely regretted. ("Gaysi") 5

This was one of the first major victories scored by the queer movement in India since the Delhi High Court decriminalisation in 2009. The short six-minute report by TV9 is just an instance of how queer cultures and identities are conceived by some sections of the media and public, recognizing it as a site of criminality where illegal sexualities are practiced and performed with the queer individuals being cast as criminals and anti-nationals. As dissident citizens, the queer community (now emboldened after the Delhi High Court decision) decided to fight back against this homophobic story. The desire to be recognized as equal citizens was at the heart of this fight; it also reclaimed the imagined safety of a space like Planet Romeo. Of course, dissident citizenship and activism extends beyond this.

Of late, the Indian media has taken an active interest in queer issues, and even regional media has started using the word queer colloquially (transcribing it in the regional alphabets). This has given rise to a whole slew of "gay celebrities." In the next section, I would like to look at two well-known lesbian activists, Sonali and Alka, who have been at the forefront of this new queer media. In doing so, I critique the creeping homonormativity and the complex mingling of activism with personal life. Dissident citizenship, I claim, is not limited to dissident movements and activism alone; it is also about the very act of existence and being able to challenge societal limitations. The defiant nature of affirming queer existence in a state that criminalizes homosexuality becomes a dissident practice. I would also like to state that in a mediatized world, the complex (and symbolic) process of uniting spatially dispersed people with similar interests and convictions is made possible through new media and cyberculture. The symbolic assemblages of acts, such as Bandyopadhyay's against TV9 and Sonali and Alka's, materialize into bodily assemblies unifying and creating a dissident queer politic.

\section{Sonali and Alka}

While the queer community in India is itself stratified in terms of gendered and classed subjectivities, it involves queer women, kothis, and hijras. This (often unsteady) alliance has been commented on by many working in this area (Dasgupta 265). Therefore, in this section I shift my focus to Sonali and Alka, ${ }^{6}$ a well-known lesbian couple and self-acclaimed queer activists in Kolkata. Sonali and Alka have been the "face" of lesbian coupledom in the media for a few years now. In a courageous move, they performed a public marriage ceremony outside a Kolkata temple on March 18, 2011, which became a talking point 
Articulating Dissident Citizenship, Belonging, and Queerness 211

among the queer communities in Kolkata and India, not just for the performative nature of it, but also for being one of the many defiant images of the queer movement in India.

Sonali and Alka have made some very high profile media appearances as their story travelled to national news networks such as NDTV as well as mainstream women's magazines such as Femina. During this period, the couple uploaded pictures of them observing the Karwa Chauth ${ }^{7}$ ceremony in their household. The patriarchal bias of the ceremony has been a sore point among feminist activists in Kolkata for a long time, and to see a lesbian couple reinforcing this heteronormative practice came as a shock to the queer community in Kolkata. A post by Sutanuka Bhattacharya critiquing this posturing of heteronormative practices by a "celebrated lesbian couple" was posted on the Facebook group of a lesbian charity on November 5, 2012, which led to more than 450 responses on the post as well as a subsequent media and legal battle. I have chosen to focus solely on this stream of debate in trying to raise a number of issues reflecting the nature of dissident citizenship within the queer movement in India.

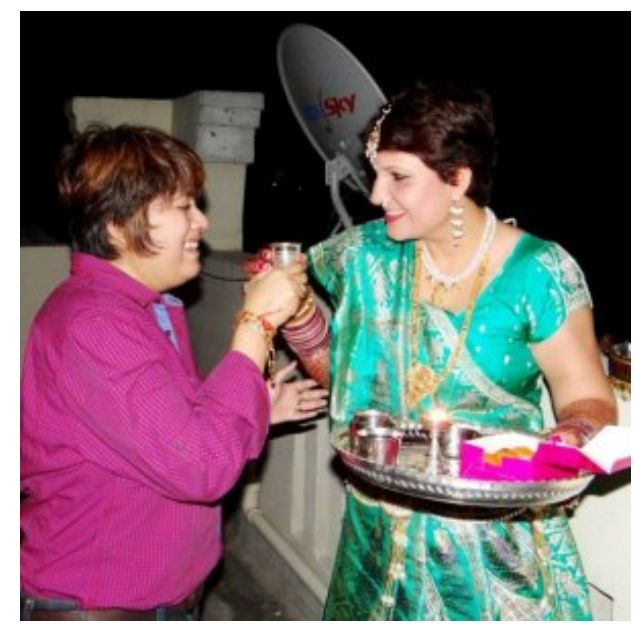

The post, which I have quoted in its entirety, raises some very interesting points about the nature of heteronormativity, class, and the issue of the personal and private space within the lives of queer activists (especially ones who are under media and public visibility):

I think it won't be irrelevant here to mention that the Karwa Chauth 2012 album came to me as a shock!! For me it is really disturbing to navigate through such an album where my fellow activists are showcasing the very heteronormative rituals which I am fighting against ... the long history of the feminist movement explains to us how patriarchy operates through such rituals. One may 
say that these are personal choices of the doers but in today's world the space provided by Facebook and other social networking sites are as much personal as political. Therefore, in such a space when I see an album like this then it is quite horrifying for me. As shown here the rituals are not restricted to an individual couple and also the rituals are not observed in a personal space. It is done in a community space, a community which is also mine. With that right I am asking Alka and Sonali who are a celebrated lesbian couple in Kolkata, my other community friends and my friends from the larger society, how do I understand these photographs, where, within young lesbian couples the "wife"/ "would be wife" or the "femme" touches the feet of the "husband" / "would-be-husband" / "butch"...where only the "wife" / "would-be-wife" / "femme" fasts for the well being/long life of their "husband" / "would-be-husband" / "butch"??? When an individual tag loaded terminologies like "owner", "founder", "activist" to her/himself then I believe lot of responsibilities and duties involuntarily also get attached to the individual ...

Second, we are first human, then women, and then queer women ... we have always worked closely with the women's movement and larger gender affinity groups, their support has been our strength. In this situation can we blindly dismiss the criticisms raised by the women's movement against these rituals?

Third, I believe exchanging gold rings and other expensive gifts as a celebration of one's couplehood is very very personal. When it crosses this personal space it is treated as exhibitionism leading to a class statement. We have friends who belong to adverse socioeconomic background, how then to understand their life struggle with such a political notion! Can a norm be set where celebration of queer couplehood can only be done through economic affluence!! ("Karwa Chauth")

Sutanuka's critique of Sonali and Alka's observation of heterosexual rites mirrors contemporary research into the family life of same sex couples that has advanced the notion that they are positioned within a heteronormative ideal. Specifically, Lisa Duggan has pointed out that this internalization of heteronormative ideals through acceptance and assimilation to heterosexual codes of conduct is what is called homonormativity (175). The boundaries of what is socially acceptable has changed over time, and Duggan has further argued that homonormativity is an expression of the sexual politics of neoliberalism that validates queer subjects with an acceptable politic, "that does not contest dominant heteronormative assumptions and institutions but upholds and sustains them while promising the possibility of a demobilized gay constituency and a privatized, depoliticized gay culture anchored in domesticity and consumption" (179). 
Articulating Dissident Citizenship, Belonging, and Queerness 213

Sonali and Alka's observation of Karwa Chauth as being an assimilation of heterosexual codes is a simplistic conclusion to be drawn from the pictures. Sonali was visibly unhappy that a picture, which was meant for personal networks and friends, had suddenly been dragged into a political debate. Sonali and Alka responded that their politics extended to visibilizing Kolkata's "invisible" lesbian population, with Alka commenting "at least we are visible to show that 2 women can be in love and can kiss also" ("Karwa Chauth"). The public nature of their relationship and the intense media scrutiny under which they had decided to live their lives meant that their actions (and photographs documenting those actions) also had a public life. One commenter, Niharika Banerjea, pointed out to them:

Unfortunately, irrespective of whether you want or not, Alka and Sonali are visible, and while they do portray a certain version of queerness, the question is: in the minds of the media and in public space that becomes representative of the entire "commumnity" [sic]. And hence, I request Alka and Sonali to be mindful of the implications of their visibility and what implications their cultural practices have on people who are unaware of the long history of queer-feminist struggle. You may say you are not political and driven by love, and I respect your love, but then your cultural practices do have deep consequences which involve more than you, thus many of us are concerned that some of your visible cultural practices are ending up reproducing those very norms that queer-feminists are struggling to change. I hope you will consider this. ("Karwa Chauth")

A simplistic critique of homonormativity and patriarchy can itself seem to be rather retrogressive as demonstrated by this debate. Rather than create a dialogue on queer politics and visibility, it created two opposing factions. J. Jack Halberstam has recently argued that as queer scholars, we are continually excavating and questioning visibility and representational politics in the public; however, we are more constrained when it comes to discussing issues of complicity at the fear of being "traitorous to a politically pure history of homosexuality" (171). Sutanuka has been quite brave in that instance not only to openly critique this "performance" but also to incite a debate which involved a large number of participants from the city's queer populace and beyond. However, for Sonali and Alka, who have been an active part of the city's queer social life by participating in Pride Day parades, pink parties, and giving a number of media bytes, the debate was a betrayal.

On November 29th, less than a month since the first post was made by Sutanuka, Sonali and Alka sent a defamation notice to Sappho for Equality, ${ }^{8}$ on whose Facebook page the initial post was first made by Sutanuka followed by the discussion that it sparked. Sonali commented on the post, making everyone aware that such a notice had been sent. 
The media also reported the incident with one reporter claiming that the couple, through their media visibility, has achieved more than the "activists have achieved in the past two decades" (Dhar). This article was widely criticized by several queer individuals in the city. Sappho's contribution to Indian queer activism is well documented and both founders remarked in an article a few years back about how the existence of lesbians need to be made visible in order to be recognized and the role of media in instigating this change (Akanksha and Malobika 363).

Sonali and Alka's celebration of Karwa Chauth mirrors the sentiments of Ruth Vanita, who has argued that Indian rituals that have historically been used in a certain way are transformed when used within the queer context (162). To read it simply as affirming to heteronormative or patriarchal ideals is a counterproductive reading, as it does not take into account the queer appropriation of it by a queer couple. What also needs to be taken into account is the classed nature of this celebration by Sonali and Alka and the spectacle of display on Facebook. While Sonali and Alka's economic and social position gave them the power to be visible in 2010, things were not the same when Sappho or the other queer organizations started in the city. Not only were these organizations and their members battling institutional and state level prejudices as dissident citizens, but they also had to battle their cultural and familial surroundings exacerbated by the fact that few have the economic freedom to walk out; many have to negotiate their presence within unfavorable surroundings.

This incident highlights that, as dissident citizens, the community has multiple voices that counter discrimination in their own wayssome through their visibility and existence, others through protest cultures and political actions. The queer dissident citizen is now focusing on identity practices and transforming their "otherness" to a new sense of belonging and thus forging a new relationship with the state and society. This incident also highlights the need to join with other movements on an intersectional level to fight oppression. Queer activism in India has always worked with other political movements, both for its survival as well for building alliances. Gay and male queer activism in India grew out of sexual health and HIV/AIDS advocacy programs (Boyce 1208). However, organizations such as Sappho grew out of the mainstream women's movement, first becoming a member of women's forums such as Maitree, then being at the forefront of all movements led by the women's rights groups, believing that if "Sappho raised its voice for their causes, they would also support us, whenever we needed them" (Akanksha and Malobika 366). There has been a schism within the movement, especially around gender and class, but, with the recent Supreme Court ruling on the December 11, 2013, it has 
Articulating Dissident Citizenship, Belonging, and Queerness 215

become imperative once more for the queer movement to build alliances with other oppressed dissident citizens to fight for their rights.

\section{Global Day of Rage: @IPC377 \#377gdr}

The government in India has historically been divided over the issue of decriminalizing homosexuality in India. When Voices Against Section 377, a Delhi-based coalition of human rights group filed an intervention in support of the original petition by Naz in 2001, the Home Ministry submitted a defence of Section 377 while the Health ministry supported a "reading down" in the later stages of the proceedings (Wintemute 32). Following the historic judgement by the Delhi High Court, which decriminalized homosexuality, various private individuals as well as a government panel were gathered to review the judgement.

The government panel decided not to participate in an appeal and to let the Supreme Court determine the "correctness" of the High Court ruling, prompting many to see this as a tacit governmental approval. However, the International Gay and Lesbian Human Rights Commission (IGLHRC) cautioned that leaving the decision to the Supreme Court was unpredictable as it might be "unwilling to intervene in moral issues." The IGLHRC's fear came true when the Supreme Court decided to reinstate Section 377 on December 11, 2013 ("IGLHRC").

The retrogressive nature of the judgement did not just impede the progress of sexual minority rights in India alone, but across the world, especially those in the global south who had taken strength from the Indian story to challenge laws and social norms in their own countries (Bangladesh, Sri Lanka and Nepal in particular). Activists were quick to respond within hours of the judgement; Twitter and Facebook were weighed down by the outrage expressed by scores of people. In an attempt to organize a collective global action, a special Global Day of Rage was announced for December 15, 2013 which would take place all around the world. 


\section{GLOBAL DAY OF RAGE}

\section{N(R)}

AHMEDABAD • BANGALORE • BHOPAL

CHENNAI • DELHI • GORAKHPUR

GUWAHATI • HYDERABAD • KOLKATA

LUCKNOW • MANGALORE • MUMBAI

MYSORE • NAGPUR • PUNE • SANGLI THRISSUR • WEST IMPHAL

ANN ARBOR • ARTESIA • BERLIN BOSTON • CAMBRIDGE • HAMBURG

HOUSTON ・ ITHACA • LONDON

LOS ANGELES • MONTREAL

NEW YORK • PHILADELPHIA

RICHMOND • SAN FRANCISCO

SYDNEY • TORONTO • VANCOUVER

The official press release condemning the judgement articulated some of the following points:

WE ARE OUTRAGED....

- That the Supreme Court of India on December 11, 2013 set aside the July 2009 Delhi High Court judgment which decriminalised consensual sex between adults in private, effectively re-criminalising all lesbian, gay, bisexual, transgender and queer Indians and reduced them to the status of "unapprehended felons."

- That the Supreme Court has failed to live up to its role as the protector of rights for all citizens without discrimination, as guaranteed by one of the world's most progressive texts- the Indian Constitution.

- That the Supreme Court has thus betrayed the fundamental constitutional promise that the dignity of all citizens would be recognised and that equal treatment is a non negotiable element of the world's largest democracy, thereby shredding the very principles it has sworn itself to uphold.

- That the Supreme Court has criminalised all consensual sexual acts that do not involve penile-vaginal penetration. This applies to all people, irrespective of their gender identity or sexual orientation, including heterosexual people and not just LGBT Indians.

- That the Supreme Court can use the phrase "miniscule minorities" to dismiss the rights of LGBT people, thus ignoring the spirit of inclusiveness which is at the heart of the Indian Constitution. The size of a minority is irrelevant, what matters is that every member of it, every Indian citizen has an equal right to protection granted by our Fundamental Rights and it is the SC"s duty to enforce this, not throw it away. ("Global Day of Rage") 
Articulating Dissident Citizenship, Belonging, and Queerness 217

The statement unambiguously makes it clear that queer citizens are no longer "others" but very much a part of the Nation. The fact that queer citizens have built alliances and been a part of the larger women's and Human rights movement is a part of the larger narrative. Sparks, writing about the dissident citizen, has contended that dissident democratic citizenship can be conceptualised as the public contestation of prevailing arrangements of power (83). The Global Day of Rage statement makes it clear that its role in protecting the rights and dignity of "all" citizens has been betrayed by choosing to refer to the queer population as the "miniscule minority" whose "so called rights" were not being infringed on by Section 377 .

One of the other complications is discerning queer as an identity (which the law does not criminalize) and queer as sexual practice (which the law vociferously puts down). This rupture in the link between the sexual identity and sexual practice, however, cannot and should not be seen separately. Sexual activity may emerge or indeed lead on from one's sexual identity, but, at the heart of the judgement, lies the regulation of moral/religious choices and state interference. Citizenship cannot be downplayed or forgotten within sexual identity politics. Ken Plummer states:

To speak of citizenship usually also implies an identity - a person, a voice, a recognised type, a locus, a position, a subjectivity-from which the claim of citizenship can be made. And such identities bring with them . . . a defining "other" different from us, and hints for future conduct based in part on this otherness. (59)

Queers occupy a particularly complex place when attempting to demarcate their claim for citizenship. They are part of multiple communities based on their gender, sexuality, class, and ethnicity (Narrain and Gupta xii). This has always posed a certain degree of confusion when trying to theorize "the" Indian citizen. While privilege might be accessed through one aspect of identity (social class, caste and so on), it is simultaneously denied by another (gender or sexuality). By denying the rights of LGBT citizens, the statement clearly implies that they become vulnerable targets to blackmailing as well as police harassment. Instances of harassment against queer people in India exist in plenty where Section 377 may or may not have been invoked (Cohen 510).

Looking only at the documented evidence where Section 377 has been invoked, the Supreme Court declared the following: "While reading down Section 377 IPC, the Division Bench of the High Court overlooked that a miniscule fraction of the country's population constitutes lesbians, gays, bisexuals or transgenders and in the last more than 150 years less than 200 persons have been prosecuted" 
(Kaushal 83). However, what the Supreme Court overlooks is the linkage between harassment, the law, and the enforcement of that law. The People's Union for Civil Liberties in Karnataka produced two reports in 2001 and 2003 where they documented the various forms of harassment and discrimination sexual minorities face within society and institutions, where in many cases Section 377 might not have been employed directly; however, the resonance of that law played an important part. Secondly, the remit of the law goes beyond the public sector. As the statement also points out it would lead to discriminatory practices within the corporate sector against their queer employees.

The final point that the statement raises is the Supreme Court's reference to the queer population as a miniscule minority. The Constitution of India guarantees the same freedom to all its citizens regardless of their actual numbers. The state of India set up the National Commission for religious minorities in 1992 and scheduled castes and tribes in 2004. Thus, in these earlier instances, the state has affirmed that the crude number of a minority group has been irrelevant to its protection under the law. The minority in question now, the queer populace, are also citizens of India and should be afforded the freedom and guarantee of equal rights and protection.

The Global Day of Rage was entirely planned and executed remotely, using social networking sites such as Facebook and Twitter. Initially, the idea was to hold a protest across several cities in India and around the world. By the end of the day, volunteers from almost thirtytwo cities across the world had signed up to take part in the protest. Within a single day, they had a logo, a press release and Twitter hashtags to document the event and keep the pressure on the Indian government.

Cultural activist Sunil Gupta proposed the London leg of the global protest, and later I joined in as one of the team of co-organisers. It was fitting and ironic that the colonial center, which had created the law in the first place, was now joining in to condemn its continual existence. A significant justification for colonial rule lay in the notion of "reform" that was created by colonizers for colonized nations. Srivastava argues that native sexual mores were regarded as the key object of such reform and held up as proof of the "moral inferiority of colonised populations ... characterised by passionate unreason and unruliness" (Srivastava 6).

Weeks argues that one of the central issues as a sexual citizen is being able to "balance the claims of different communities . . . affirming the importance of collective endeavours" (49). Similarly, the Global Day of Rage movement in London targeted not just the queer organizations for support but also women's rights and South Asia specific organizations. It was much to our surprise that diverse 
Articulating Dissident Citizenship, Belonging, and Queerness 219

organizations such as Southall Black Sisters, SARBAT (the Sikh LGBT support group) as well as allies from trade unions provided us with overwhelming support. The protest received widespread coverage from the global media with UK-based celebrities and activists such as Stephen Fry and Peter Tatchell supporting it on Twitter and media outlets such as BBC and Pink News reporting on the event. The protest also provided a platform for people to speak up about how they have been affected by the decision and how they would like to keep the fight on. UK-based organizations were especially encouraged to speak up, and it was interesting to hear how the resonance of Section 377 was felt within the South Asian community in Britain.

\section{Coda}

The year of 2014 is a defining year for queer politics in India. The positive recognition of queer people by the law has been accompanied by broader acceptance of queer people in public culture, as numerous media stories testify. This article has attempted to emphasize the role of new media in structuring and critiquing the nature of queer politics in India. As Narrain and Gupta eloquently note, "even though the Naz decision effectively only decriminalise[d] sodomy, at its heart it is about positive recognition of the right to love" (xi).

Dave has argued that, within a democratic system, certain forms of political speech are rendered intelligible while other forms are rendered silent (161). In this article, I have discussed a range of dissident actors who offer a discursive voice rendering the public emergence of the queer citizen in India, ranging from political articulations of Indianness to dissident activism. While writing this article, I wanted to tell the untold stories of dissident actors on the cyber space, but I also wanted to reflect critically on the directions of the Indian queer movement. Arvind Narrain and Gautam Bhan have questioned how a queer language can describe India, given that the idea of an inclusive and tolerant nation continues to be challenged by brutalities in maintaining a "pure" caste, class, religion and so on (2). In fact, recent events such as the rape of Nirbhaya in Delhi, atrocities against the African population in India, and the swing to the right in the political polls signal this rupture.

As I have explained, the real danger of Section 377 lies in the fact that it exists beyond the pages of the law, permeating our social lives, media representations and popular discourse. Incidents such as TV9 become a rallying point for the queer community. The emergence of a vocal queer voice is also present in the widened nature of the movement as evidenced by the Global Day of Rage across the world. The movement no longer exists only through queer identified people but a whole range of actors and coalition groups (Voices against 
Section 377 is one of the prominent ones amongst them), reflecting the intersectional nature of the movement.

New media and the internet offer queer people the opportunity to construct a public identity and speak to a public, offering a sense of democracy. They are engaged in creating a citizenry that challenges the power of heteronormativity. Dissident citizenship also takes the form of counter-public, an area where subordinate social groups regroup and circulate counter discourses. The lives of queer people in India as dissident citizens lie at the core of this article. Through ethnographic narratives, I show the critical solidarity of the movement and creative acts of resistance, be it through queering heteronormative practices as Sonali and Alka have done, or political and social resistance through campaigns against the TV9 controversy like the Global Day of Rage movement. As this article has argued, dissenting practices take many forms-from discursive and performative to organizational and everyday dissent. Identity politics gets convoluted when dissident sexualities are placed within the discourse of the nation state. The emergence and validation of queer identities encourages one to examine the impact of class, gender, and sexuality on democratic participation in India.

\section{Acknowledgements}

I would like to thank Dr. Sara Davidmann, Dr. Sharif Mowlabocus, Professor William Raban, and Sunil Gupta for offering extensive feedback on this paper. I would also like to thank Debanuj Dasgupta, Dr. Matthew Legatt and Dr. Caroline Williams, who have influenced and enriched this article in so many ways. The research was funded by the University of the Arts London International Graduate Studentship. I would also like to thank the anonymous reviewers for their feedback and the Special Issue editors Umme Al Wazedi and Madhurima Chakraborty.

\section{Notes}

1. Partha Chatterjee defines civil society as elite construct, which includes all social institutions outside the strict domain of the state and considers the political society as a more appropriate way of reflecting on the politics and engagement of the modern world (39). Democratic politics involves this constant shift between compromising values of modernity and the moral assertions of popular demands. The civil society is restricted to only a few and, according to Chatterjee, it needs to work alongside the political society for any legitimate change to take place.

2. This research was conducted between 2011 and 2014 as part of my doctoral study, which received ethical clearance from the Research Degree Committee in December 2011.

3. Gaysi is a short form of Gay desi, a popular Gay news website based in India. 


\section{Articulating Dissident Citizenship, Belonging, and Queerness 221}

4. This is available on the order issued by NBSA to TV9 Hyderabad. A copy of this was asked to be made available to all viewers who had complained by the Ministry of Information and Broadcasting. This was uploaded on the Gaysi website.

5. The video of the apology titled, "We won! TV9 has apologized," can be viewed on YouTube.

6. I had initially decided to use pseudonyms for Sonali and Alka but then decided against it. Both Sonali and Alka are well known within the queer circles, and it would not have helped disguise the case by a simple changing of names. Also, because of the nature of the case, which made its way to several media outlets, I did not feel there was an ethical necessity to safeguard individual privacy. Sharad Chari and Henrike Donner have commented that activism is about solidarity through reciprocity (75). While I stand in solidarity with these two activists, it is also essential that my solidarity and commitment are also reflective of the practices and ongoing discourse within the queer movement in Kolkata, not let this forging of solidarity overshadow the critical and confrontational nature of queer activism.

7. Karwa Chauth is a one-day festival celebrated by Hindu women in North India, where they fast between sunrise and sunset for the safety and longevity of their husbands. The fast is broken by the women after viewing the reflection of the rising moon through a sieve and then facing their husbands who offer them a sip of water and the first morsel of the day. This festival has been criticized for being inherently sexist and perpetuating the notion of women's dependence on men.

8. Sappho for Equality is the only registered collective in Eastern India working for the rights of lesbian, bisexual women and trans men. The gendered and sexual experiences of female bodied and male bodied persons have different trajectories, hence Sappho for Equality mobilizes around the concerns of female bodied lesbians, bisexual women and female to male transmen (Banerjea 12).

\section{Works Cited}

Ahmed, Sara. The Cultural Politics of Emotion. Durham: Duke UP, 2004. Print.

Akanksha, and Malobika. "Sappho a journey through Fire." The Phobic and Erotic. Eds. Brinda Bose and Shuddhabrata Bhattacharya. Calcutta: Seagull, 2007. 363-68. Print.

AllOutorg. "We won! TV9 has apologized." YouTube. 29 Mar. 2011. Web. 5 Jan. 2014.

Bachcheta, Paola. "When the (Hindu) Nation Exiles its Queers." Social Text 61 (1999): 141-66. Print.

Ballhatchet, Kenneth. Race, Sex and Class Under the Raj. London: Weidenfeld and Nicholson, 1980. Print.

Bandyopadhyay, Aditya. "TV9.” Facebook.com. 23 Feb. 2011. Web. 23 Dec. 2013.

Banerjea, Niharika. "Critical Urban Collaborative Ethnographies: Articulating Community with Sappho for Equality in Kolkata, India." Gender, Place 
and Culture: A Journal of Feminist Geography. 8 Aug. 2014. Web. 15 Nov. 2014.

Bose, Brinda, and Shuddhabrata Bhattacharya. Introduction. The Phobic and Erotic. Eds. Brinda Bose and Shuddhabrata Bhattacharya. Calcutta: Seagull, 2007. ix-xxxii. Print.

Boyce, Paul. "Desirable rights: same-sex sexual subjectivities, socio- economic transformations, global flows and boundaries in India and beyond." Culture, Health \& Sexuality: An International Journal for Research, Intervention and Care 16.10 (2014): 1201-15. Print.

Chari, Sharad, and Henrik Donner. "Ethnographies of Activism: A Critical Introduction." Cultural Dynamics 22.2 (2010): 75-85. Print.

Chatterjee, Partha. The Politics of the Governed: Reflections on Popular Politics in Most of the World. New York: Columbia UP, 2004. Print.

Cohen, Lawrence. "Song for Pushkin". Law like Love. Eds. Arvind Narrain and Alok Gupta. New Delhi: Yoda, 2011: 510-29. Print.

Dasgupta, Rohit K. "Parties, Advocacy and Activism: Interrogating Community and Class in Digital Queer India." Queer Youth and Media. Ed. Christopher Pullen. Basingstoke: Palgrave Macmillan, 2014: 265-77. Print.

Dave, Naisargi. Queer Activism in India: An Anthropology in Ethics. Durham: Duke UP, 2012. Print.

Dhar, Udayan. Karwa Chauth Wars: Kolkata Lesbian Couple Harassed by LGBT Advocates. Pink Pages India. 5 Dec. 2012. Web. 5 Jan. 2014.

Duggan, Lisa. "The New Homonormativity: The Sexual Politics of Neoliberalism." Materialising Democracy: Towards a Revitalised Cultural Politics. Ed. Russ Castronovo. Durham: Duke UP, 2002. 175-94. Print.

Evans, David. Sexual Citizenship: The Material Construction of Sexualities. London: Routledge, 1993. Print.

“Gaysi: TV9's Homophobic Coverage”. Gaysi. 23 Feb. 2011. Web. 5 Jan. 2014.

“Global Day of Rage”. Facebook. 13 Dec. 2013. Web. 5 Jan. 2014.

Halberstam, J. Jack. The Queer Art of Failure. Durham: Duke UP, 2011. Print.

"IGLHRC: Indian Government Defers decision on 377 to Supreme Court." IGLHRC.org. 18 Sept. 2009. Web. 23 Dec. 2013.

"Karwa Chauth: Sappho for Equality Facebook Page." Facebook. 5 Nov. 2012. Web. 23 Dec. 2013.

Kaushal, Suresh Kumar. "Suresh Kumar Kaushal vs NAZ Foundation and others, Supreme Court of India." Judis.nic.in. 11 Dec. 2013. Web. 5 Jan. 2014.

Kugle, Scott. "Sultan Mahmud's Makeover: Colonial Homophobia and the Persian-Urdu Literary Tradition." Queering India: Same Sex Love and Eroticism in Indian Culture and Society. Ed. Ruth Vanita. London: Routledge, 2002. 30-46. Print.

Mowlabocus, Sharif. Gaydar Culture: Gay men, Technology and Embodiment in the Digital Age. Farnham: Ashgate, 2010. Print.

Narrain, Arvind, and Gautam Bhan. Because I have a Voice. New Delhi: Yoda, 2005. Print. 
Articulating Dissident Citizenship, Belonging, and Queerness 223

-, and Alok Gupta. Law Like Love: Queer Perspectives on Law. New Delhi: Yoda, 2011. Print.

Plummer, Ken. Intimate Citizenship: Private Decisions and Public Dialogues. Seattle: U of Washington P, 2003. Print.

Sparks, Holloway. "Dissident Citizenship: Democratic Theory, Political Courage, and Activist Women." Hypatia 12.4 (1997): 74-110. Print.

Spivak, Gayatri, and Judith Butler. Who Sings the Nation State? Calcutta: Seagull, 2011. Print

Srivastava, Sanjay. Sexuality Studies. New Delhi: OUP, 2013. Print.

Vanita, Ruth. Love's Rite: Same Sex marriage in India and the West. New Delhi: Penguin, 2005. Print.

Weeks, Jeffrey. "The Sexual Citizen." Theory, Culture and Society 15.3 (1998): 35-52. Print.

Wintemute, Robert. "Same-sex love and Indian penal code 377: An important human rights issue for India." NUJS Law Review 4 (2011): 31-65. Print. 